\title{
DESVENDANDO O PROCESSO CRIATIVO DA TRADUÇÃO DA PEÇA DE ATHOL FUGARD, "STATE-MENTS AFTER AN ARREST UNDER THE IMMORALITY ACT”
}

\author{
UNDERSTANDING THE CREATIVE PROCESS OF TRANSLATION OF THE
} PART OF ATHOL FUGARD, "STATEMENTS AFTER AN ARREST UNDER THE IMMORALITYACT"

Raquel Borges Dias UFBA/CAPES

Sílvia Maria Guerra Anastácio

Instituto de Letras-UFBA

\begin{abstract}
Resumo: $O$ objetivo deste trabalho é apresentar os resultados parciais da tese de doutorado $O$ proces-so de criação da tradução da peça "Statements after an arrest under the Immorality Act", de Athol Fugard. Buscamos reconstituir o percurso criativo do texto em estado nascente com o objetivo de nos aproximarmos da forma como a obra foi concebida e realizada, através da análise dos manuscritos deixados pelos artistas (BIASI, 2000). A partir da análise do pro-cesso de criação da tradução da peça de Athol Fugard do inglês para o português, reflexões sobre aspectos culturais, bem como, o contexto social, político e histórico da obra traduzida será levado em consideração (TOURY, 1995). Também, será interessante trabalhar com o conceito de funcionalidade da tradução, a fim de refletir acerca da função do texto tradu-zido na cultura de chegada (VERMEER, 2014 [1984]). Além disso, estudos sobre estran-geirização e domesticação serão relevantes para a investigação aqui delimitada (VENUTI, 2002), a fim de que se possam verificar indícios, nos documentos de processo, que auxiliem na análise do processo criativo que esta tese se propõe a pesquisar.
\end{abstract}

Palabras-chave: Tradução, Processo de criação, Athol Fugard, Statements.

\begin{abstract}
This paper aims to present partial results of the doctoral thesis The creative process of the translation of the play "Statements after an arrest under the Immorality Act", by Athol Fu-gard. We try to reconstitute the creative course of the text in nascent state with the purpose of approaching the way the work was conceived and performed, through the analysis of the manuscripts left by the artists (BIASI, 2000). From the analysis of the creative process of the translation of Athol Fugard's play from English into Portuguese, reflections on cultural as-pects, as well as the social, political and historical context of the translated work will be tak-en into account (TOURY, 1995). Also, it will be interesting to work with the concept of skop-os theory of translation, in order to reflect on the function of the translated text in the target culture (VERMEER, 2014 [1984]). In addition, studies on foreignization and domestication will be relevant to the research delimited here (VENUTI, 2002), so that evidence can be found in the process documents that will help in the analysis of the creative process that this thesis proposes to research.
\end{abstract}

Key words: Translation, Creation process, Athol Fugard, Statements. 


\section{Introdução}

O dramaturgo, romancista e diretor Harold Athol Lanigan Fugard, mundialmente conhecido como Athol Fugard, nasceu em 1932, em Middelburg, na Província do Cabo, África do Sul. Caracterizado por seu engajamento em questões políticas e direitos humanos, apoiou o movimento contra o Apartheid por mais de trinta anos, o que o levou a ser vigiado pela polícia e a sofrer restrições do governo. Com isso, o autor começou a produzir peças com ampla divulgação fora de seu país, as quais espelharam a forte consciência dos problemas locais e que passou a divulgar para todo o mundo.

Autor de obras mundialmente conhecidas, tais como, "Master Harold"... and the Boys (1982), The Road to Mecca (1984) e Tsotsi: a novel (1980), uma das peças mais relevantes de Athol Fugard é "Statements after an arrest under the Immorality Act” (1974). O texto dramático de Fugard demonstra a consciência social do autor frente ao contexto em que a África do Sul se encontrava na década de 1970 (O’NEIL, 2004), ao retratar o envolvimento de uma mulher branca com um homem mestiço; tal relação era um desafio ao regime do Apartheid e à Lei da Imoralidade que, na África do Sul, proibia relações sexuais inter -raciais.

Considerando a grande importância da obra de Fugard para a literatura e a cultura mundiais, a peça foi traduzida do inglês para o português por pesquisadores de iniciação científica entre 2011 e 2012. Assim, o objetivo da tese de doutorado da presente pesquisadora é investigar o processo de criação da tradução da peça "Statements after an arrest under the Immorality Act” (1974) de Athol Fugard, que consiste em uma contribuição inovadora para os estudos do processo de criação acerca da referida obra, inédita em língua portuguesa e, ainda, considerando que tais manuscritos de trabalho não foram analisados anteriormente.

Considerando que todo o processo de produção da tradução da obra de Fugard para o português foi realizado em meio digital, propomos analisar tal dinâmica criadora sob o olhar de aspectos teóricos, que julgamos relevantes para esta pesquisa. Dessa forma, uma análise interpretativa do material será proposta, a fim de que os documentos do processo em estudo possam estar disponíveis para um número maior de pesquisadores de crítica genética e áreas afins.

\section{O processo de criação da tradução da obra de Athol Fugard}

O processo de criação em análise parte de um dossiê digital, que traz, ao todo, cinco versões da tradução interlingual realizada, no período de setembro de 2011 a maio de 2012. O processo tradutório apoiou-se no eixo teórico-metodológico da crítica genética, destacando a utilização dos operadores genéticos, que facilitaram a identificação e análise dos movimentos de gênese ocorridos, durante o processo de construção do texto traduzido. Compõem o dossiê cinco versões de tradução, disponíveis em arquivos do Programa Microsoft Office Word 2007, que apresentam comentários feitos em balões, na margem direita da página; estes revelam pesquisas feitas na internet, trazem ilustrações e links de sites visitados, de consultas a dicionários, além de apresentarem a datação e o nome dos pesquisadores envolvidos em cada etapa do trabalho. As versões de tradução foram nomeadas e numeradas, sendo identificadas da seguinte forma:

- ST - indicação de que o documento de processo pertence ao dossiê "Statements..." (separado por vírgula do código seguinte);

- v - indicação do número da versão do texto 
Figura 1. ST, v 1 p. 81 (Fonte: Dossiê Genético Digital "Statements...", 2012)

VERSÃO 1

LUANA LISE CARMO DA SOLIDADE

RAFAELA BISINOTTO GOMES

\section{DECLARAÇÕES/ AFIRMAÇÕES/DEPOIMENTOS APÓS A DETENÇÃO/ PRISÃO SOB/ DEVIDO A UM/O ATO IMORAL/ DE IMORALIDADE}

\section{PÁGINA 81}

traduzido, seguido do número correspondente - rev - indicação do número da revisão da versão, nos casos em que a versão tiver mais de um documento, seguida do número correspondente;

- p. - indica o número da página correspondente ao texto traduzido, uma vez que a numeração das páginas dos documentos foi realizada de acordo com o texto em língua inglesa;

- pp. - indica o número da página correspondente ao texto traduzido, no caso do trecho abranger mais de uma página.

Assim,

ST, $v 1$ rev 2 p. 98 - indica o documento de processo do dossiê "Statements...", versão número 1 , segunda revisão, página 98.

As etapas de organização dos documentos de um acervo foram didaticamente explicadas por Pierre-Marc de Biasi em seu livro A genética dos textos (2010), no capítulo quatro, em que o autor discorre sobre o tema "Análise dos manuscritos: princípios e métodos".

No presente artigo, analisaremos alguns documentos de processo da tradução do dossiê "Statements...", que focalizam a escolha do tí-

1 Diferentemente de $v^{\circ}$, que corresponde ao verso de determinado fólio (BIASI, 2010), que não se aplicará no referido estudo, uma vez que, nos documentos digitais, trabalhamos apenas com o reto do documento. tulo da obra de Fugard em português, uma vez que apresenta movimentos genéticos importantes, principalmente por trazerem para discussão o contexto histórico e político do texto traduzido. Com isso, mostraremos como o título foi criado e modificado, ao longo dessas versões tradutórias.

Inicialmente, ao observarmos o trabalho com o título da obra, podemos verificar que foram, inicialmente, indicadas diferentes opções de tradução para o termo statements: "DECLARAÇÕES/ AFIRMAÇÕES/ DEPOIMENTOS”, bem como, outras opções, que constam do balão de comentários WX2, indicado na margem direita do documento:

Dentre as opções apresentadas para o verbete statement, "Declaração/ Afirmação/ Manifesto/ Relação/ Lista/ Demonstração de contas/ Relatório/ Depoimento” (ST, v 1 p. 81), vale ressaltar a inserção de um comentário: "Political statement, any act or nonverbal form of communication that is intended to influence a decision to be made for or by a group". Apesar de não trazer a fonte de pesquisa, tal informação é relevante, considerando o título da peça a ser traduzido para o português². Pelas informações

2 Após algumas pesquisas, pudemos verificar que o trecho apresentado no balão de comentários havia sido retirado do livro Political Communication: A Multi-Disciplinary Explora- 
sugeridas, podemos notar que o verbete statement pode se referir a uma declaração política, a uma lei ou a uma forma de comunicação não verbal, que venha a influenciar alguma decisão a ser tomada. Tais significados marcadamente políticos nos remetem ao contexto histórico da obra, narrativizado por Fugard.

Por um lado, Frieda representa a parcela mais favorecida da população, uma vez que teria seus direitos garantidos politicamente por ser branca; por outro lado, Joubert representa a população subjugada pelos governantes, o povo afastado das áreas de convivência da região central, arbitrariamente colocado em regiões periféricas, aceitando as migalhas cedidas pelo governo. Apesar de os brancos estarem em uma posição mais favorecida, também, lhes é vedado o direito à liberdade, considerando o fato de que foi criada, pelo Partido Nacional, uma série de leis que proibia o relacionamento inter-racial e, mesmo, as relações íntimas fora do casamento.

Este grupo político, apesar de representar a menor parcela da sociedade, conseguiu implantar o regime do Apartheid na África do Sul, levando o preconceito racista a um extremo inimaginável. De maneira desumana e sórdida, o sistema de segregação racial foi imposto por meio do poderio militar, restringindo os direitos à liberdade de ir e vir, bem como, aplicando uma

tion, de Lauren Cohen Bell (2012). O livro apresenta uma definição de alguns termos, tal qual pode ser observado na entrada que define o verbete statement: "Statement may refer to: - A kind of expression in language (linguistics)/ Statement declarative sentence that is either true or false [...] Political statement, any act or nonverbal form of communication that is intended to influence a decision to be made for or by a group [...]" (BELL, 2012) - "Uma declaração pode referir-se a: - Um tipo de expressão na linguagem (linguística)/ Frase declarativa que pode ser verdadeira ou falsa [...] Declaração política, qualquer lei ou comunicação não-verbal que se destina a influenciar uma decisão a ser tomada para ou por um grupo [...]" (BELL, 2012, online, tradução nossa). discriminação racial, que não respeitava nem mesmo os relacionamentos pessoais e conjugais. As leis opressivas legitimavam o poder absoluto de uma minoria de cor branca, punindo qualquer oposição a esse regime político.

Retomando o processo de criação da tradução da obra, interessa-nos observar os documentos da terceira versão de revisão do texto (ST, v 3). Apesar da tradução já ter sido revisada pelo grupo, pudemos observar, ao longo do texto, que ainda havia dúvidas acerca da escoIha de alguns vocábulos. Por isso, foi decidido pelos pesquisadores enviar o arquivo para uma consultora, falante nativa de língua inglesa, que faria uma nova revisão do texto traduzido.

Tal consulta demonstrou ser uma etapa importante, pois a tradução pode ser analisada sob três ângulos diferentes: a) do texto de partida - Fugard - em inglês; b) do texto de chegada - em português; c) do texto revisado por uma falante nativa de língua inglesa, capaz de contribuir com explicações quanto a aspectos culturais, especialmente da cultura de partida.

A colaboradora, além de trazer diferentes soluções tradutórias para as dúvidas apresentadas, acrescenta comentários com aspectos históricos relevantes para o trabalho realizado, de forma a enriquecer o processo de tradução em andamento. Logo no começo do documento ST, v 4 p. 81 (FIGURA 2), é interessante ressaltar a importante contribuição dada pela revisora:

A revisora chama atenção para o processo tradutório de alguns vocábulos utilizados pelos pesquisadores: inicialmente, retira a expressão "UM ATO IMORAL", como pode ser observado pelo uso dos operadores genéticos e acrescenta "UMA INFRAÇÃO À LEI DA IMORALIDADE". Ainda, a colaboradora questiona se tal opção abrangeria a ideia de ilegalidade proposta na versão em inglês, uma vez que os personagens haviam transgredido a lei, de forma que a polí- 
Ffigura 2. ST, v 4 p. 81 (Fonte: Dossiê Genético Digital "Statements...", 2012)

\title{
DEPOIMENTOS APÓS O FLAGRANTE DE [UM ATO \\ IMORAL] \\ $<$ UMA INFRAÇÃO > [DETENÇÃO ILEGAL CONTRA A] À \\ $<$ LEI DA IMORALIDADE $>$
}

(note- this is a good translation of the title, but does it contain the idea of illegality i.e. the law has been broken and the police are involved? The word 'Act' in the original title means 'Lei' not 'ato'. 'Arrest' is 'detencão')

\section{PÁGINA 81}

\begin{abstract}
Um homem e uma mulher em cima de um cobertor no chão. Ambos estão nus. Ele está acariciando o cabelo dela.

Poucaluz.

MULHER: (timidamente). Sequei meu cabelo ao sol. Só ali, sentada, numa cadeira do quintal, sentindo o calor do sol na minha cabeça. Podia sentir cada fio de cabelo e minha cabeça parecia muito leve... A textura do cabelo muda enquanto ele vai secando. E depois, então, sinto o cheiro do meu cabelo quando [ele] cai [sobre o] <no $>$ meu rosto... cheiro de cabelo limpo e de shampoo. Quanto mais sece [cálido] <aquecido o cabelo fica> [ao sol] (note - warmer not drier - the sun is making the hair hot) [ele fica], mais [você] <se > pode sentir o seu cheiro. E se houver qualquer brisa, nem que seja fraca, veja o jeito como ele levanta e flutua. Além disso... a cor dos fios, especialmente quando eles caem perto de seus olhos... A cor parece viva. Pausa. O tempo parece parar. Tudo fica muito quieto. Apenas os sons de uma tarde quente ... sons quentes, cheiros
\end{abstract}

cia estava envolvida para resolver o caso. Ainda, acrescenta que a palavra Act, no contexto, não está se referindo a um "Ato", mas a uma "Lei", e informa que Arrest alude à "Detenção". Desta forma, a revisora propõe o seguinte título para a obra: "Depoimentos após o flagrante de uma infração à Lei da Imoralidade”. Com isso, há uma aproximação com o contexto sócio histórico da obra de partida.

É interessante observar a utilização da expressão "Lei da Imoralidade", neste contexto. O sistema do Apartheid, partindo do princípio da discriminação e da segregação racial, interferia em todos os aspectos da vida social na África do Sul. Ao longo do período deste regime, foram estabelecidas diversas proibições acerca do relacionamento inter-racial, o qual se tornou, cada vez mais restritivo, com o passar do tempo. A Lei da Imoralidade, que já havia sido promulgada em 26 de março de 1927, antes mesmo da implantação do Apartheid, proibia qualquer relação sexual considerada ilícita entre "europeus" e "nativos", quer fossem homens ou mulheres. A expressão "nativos" incluía membros de qualquer raça aborígene ou tribal da África. A punição contra o crime era de até cinco anos de reclusão.

Em 1949, foi publicada uma lei, que proibia casamentos inter-raciais na África do Sul, além de rejeitar relacionamentos sexuais fora do casamento entre pessoas que não fossem da mesma etnia. Em 1950, o Parlamento sul-africano lançou uma lei com o objetivo de registrar todos os habitantes da África do Sul, de acordo com as classificações raciais determinadas pelo regime do Apartheid: Black ("Negros"), White ("Brancos"), Coloured (Pessoas "de cor" ou "mestiços") e Indians ("Indianos"). No mesmo ano, foi publicada uma emenda à Lei da Imoralidade de 1927, proibindo o relacionamento entre europeus e 
não-europeus, tornando ato criminoso o fato de uma pessoa de cor branca ter relações sexuais com uma de outra raça. Levando em consideração tais leis estipuladas por governantes da época do Apartheid e as dificuldades diárias vivenciadas pelos habitantes daquela região, Athol Fugard lança sua obra como uma resposta à lei, que proibia o contato íntimo entre brancos e qualquer outro grupo étnico (O'NEIL, 2004).

Certamente, com o desenvolvimento da pesquisa, os estudos acerca do referido processo criativo de tradução da obra de Fugard para o português poderão ser aprofundados, de forma que os resultados sejam disponibilizados para os pesquisadores interessados no assunto.

\section{Considerações finais}

Os relatos da gênese apresentados, até então, demonstram a importância de levarmos em consideração aspectos do contexto sócio histórico da obra de partida, que perpassam diferentes documentos de processo. Também, é possível verificar como diferentes atores do processo de tradução interferem no resultado final, sendo necessário o acesso ao maior número de documentos possível para se ter uma visão mais clara de como uma produção ocorreu. Certamente, podemos concluir que o texto de Fugard revela diversas questões a serem debatidas, que incitam o leitor a assumir uma postura crítica diante de um regime segregacionista.

\section{Referências}

BELL, Lauren Cohen. Political Communication: A Multi-Disciplinary Exploration. (2012). Disponível em: <https://books.google.com. br/books?id=LIJW_EbOPzIC\&pg=PT24\&lp$g=P T 24 \& d q=\% E 2 \% 80 \% 9$ CPolitical+statement,+any+act+or+nonverbal+form+of+communication+that+is+intended+to+influen$c e+a+$ decision+to+be+made+for+or+by+a+- group \%E2\% 80\%9D\&source=b|\&ots $=Z$ t 8DKxtApP\&sig=8A Ji1N7K9oF8QFI274uPz89F2tE\&hl=pt-BR\&sa=X\&ved=0ahUKEwjRmuXxkNvbAhXBiZAKHUnJDH0Q6AEIKDAA\#v=0nepage\&q\&f=true>. Acesso em: 17 jan. 2018.

BIASI, Pierre-Marc de. Análise dos manuscritos: princípios e métodos. In: BIASI, Pierre-Marc de. A genética dos textos. Tradução de Marie -Hélène Paret Passos. Porto Alegre: EDIPUCRS, 2010. p. 67-90.

FUGARD, Athol. "Depoimentos Após o Flagrante de uma Infração à Lei da Imoralidade". Tradução realizada por Pesquisadores de Iniciação Científica. Salvador: UFBA, 2012. (Obra não publicada)

FUGARD, Athol. "Master Harold"... and the Boys. New York and London: Penguin, 1984 [1982].

FUGARD, Athol. "Statements after an arrest under the Immorality Act”. In: FUGARD, Athol; KANI, John; NTSHONA, Winston. Statements: Three Plays - Sizwe Bansi is Dead; The Island; Statements after an arrest under the Immorality Act. New York: Theatre Communication Group, 1974.

FUGARD, Athol. The Road to Mecca: A Play in two Acts. London: Faber and Faber, 1985 [1984].

FUGARD, Athol. Tsotsi: a novel. New York: Random House, 1980.

O’NEIL, Patrick M. "Athol Fugard”. In: O’NEIL, Patrick M. (Ed.). Great World Writers: Twentieth Century. v. 3. New York: Marshall Cavendish, 2004. p. 359-376. Disponível em: <http://www. questia.com/read/119886357/great-world-writers-twentieth-century>. Acesso em: 29 maio 2016. 